\title{
A POLÍTICA PÚBLICA PREVIDENCIÁRIA E A JUSTIÇA FEDERAL: 0 ACESSO AOS BENEFÍCIOS PELOS SEGURADOS ESPECIAIS INDÍGENAS NOS MUNICÍPIOS DE PORTO SEGURO E EUNÁPOLIS/BA
}

\author{
AUTOR: RÔMULO ALMEIDA ADORNO \\ CO-AUTOR/ORIENTADOR: DANIELA ROCHA TEIXEIRA
}

Resumo: O presente trabalho tem por intuito ir além dos estudos de sala de aula sobre Direito Previdenciário, fazendo uma pesquisa com um viés de abordagem sobre a efetividade na aplicação local das normas brasileiras sobre o tema, aproximando-se ao da comunidade que se avizinha, indígena, a qual, também, vive a Universidade, e fomentar o poder de questionar a sua realidade e de seu entorno, a partir dos conhecimentos de humanidades e jurídicos adquiridos. Inicialmente, a metodologia de pesquisa adotada foi qualitativa-quantitativa, mas dificuldades quanto ao sistema do INSS e da Justiça Federal, impulsionados pela paralisação das atividades presenciais motivadas pelo Corona Vírus impossibilitaram a continuação das atividades quantitativas, restando a análise documental do estado da arte sobre o tema. Algumas hipóteses de investigação foram pensadas no decorrer do trabalho, sendo elas voltadas a verificar se os segurados especiais indígenas da região se encontram em estado de vulnerabilidade social e, em caso positivo, se essa vulnerabilidade intensifica a dificuldade no acesso aos benefícios previdenciários, que são direitos constitucionais. $O$ óbice quanto ao acesso aos dados quantitativos impediu a verificação dessas hipóteses, mas índices gerais mostram que uma alta porcentagem de indígenas não são alfabetizados, o que é indício de que se encontram, de fato, em estado de vulnerabilidade social, que, aliado à burocracia existente nas instituições do Poder público, podem intensificar a dificuldade desses atores em acesso a benefícios previdenciários.

Palavras-chave: Benefícios previdenciários, Segurados especiais, Indígenas. 